LONG-RANGE OIL AND GAS

FORECASTING METHODOLOGIES:

LITERATURE SURVEY

E.A. Cherniavsky

August 1980

Prepared for the

OIL AND GAS ANALYSIS DIVISION

ENERGY INFORMATION ADMINISTRATION

UNITED STATES DEPARTMENT OF ENERGY

NATIONAL CENTER FOR ANALYSIS OF ENERGY SYSTEMS

DEPARTMENT OF ENERGY AND ENVIRONMENT

BROOKHAVEN NATIONAL LABORATORY

UPTON, NEW YORK 11973

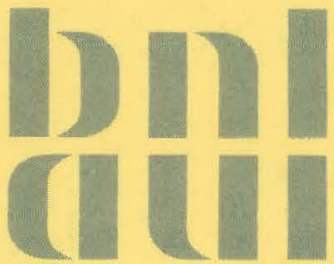




\section{DISCLAIMER}

This report was prepared as an account of work sponsored by an agency of the United States Government. Neither the United States Government nor any agency Thereof, nor any of their employees, makes any warranty, express or implied, or assumes any legal liability or responsibility for the accuracy, completeness, or usefulness of any information, apparatus, product, or process disclosed, or represents that its use would not infringe privately owned rights. Reference herein to any specific commercial product, process, or service by trade name, trademark, manufacturer, or otherwise does not necessarily constitute or imply its endorsement, recommendation, or favoring by the United States Government or any agency thereof. The views and opinions of authors expressed herein do not necessarily state or reflect those of the United States Government or any agency thereof. 


\section{DISCLAIMER}

Portions of this document may be illegible in electronic image products. Images are produced from the best available original document. 
BNL 51216

UC-92

(Petroleum and Natural Gas -

TI(-4500)

\title{
LONG-RANGE OIL AND GAS FORECASTING METHODOLOGIES: LITERATURE SURVEY
}

\author{
E.A. Cherniavsky
}

August 1980

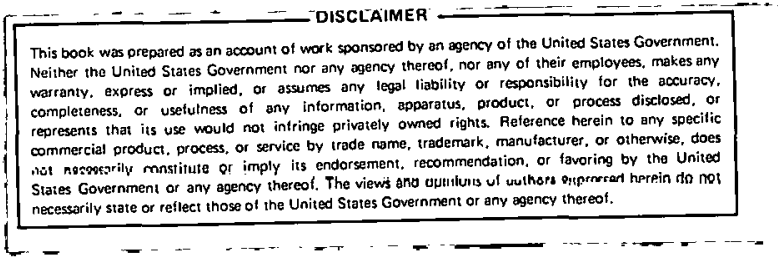

NATIONAL CENTER FOR ANALYSIS OF ENERGY SYSTEMS DEPARTMENT OF ENERGY AND ENVIRONMENT BROOKHAVEN NATIONAL LABORATORY ASSOCIATED UNIVERSITIES, INC.

\section{UNDER CONTRACT NO. DE-AC02-76CH00016 WITH THE UNITED STATES DEPARTMENT OF ENERGY}




\section{DISCLAIMER}

This report was prepared as an account of work sponsored hy an agency of the United States Government. Neither the United States Government nor any agency therenf, nor any of their employees, nor any of their contractors, subcontractors, or their employees, makes any warranty, express or implied, or assumes any legal liability or responsibility for the accuracy, completeness, or useful ness of any information, apparu tus, product, or process disclosed, or represents that its use would not infringe pri-

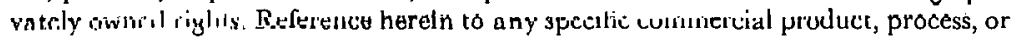
service by trade name, trademark, manufacturer, or otherwise, does not necessarily constitute or imply its endorsement, recommendation, or favoring by the United States Government or any agency, contractor or subcontractor thereof. The views and opinions of authors expressed herein do not ncccssarily state ur reflect those of the United States Government or any agency, contractor or subcontractor thereof.

Printed in the United States of America

Available from

National Technical Information Service

U.S. Department of Commerce

5285 Port Royal Road

Springfield, VA 22161

Price: Printed Copy $\$ 6.00$; Microfiche $\$ 3.50$ 


\section{ABSTRACT}

Performance of long-range energy system analyses requires the capability to project conventional domestic oil and gas supplies in the long term. The objective of the Long-range Forecasting Methodology project is to formulate an approach to this problem which will be compatible with the principal tool employed by the Energy Information Administration of the Department of Energy for long-range energy system analyses, the Long-term Energy Analysis Package (LEAP). This paper reports on projection methodologies that have appeared in the literature, evaluates them in terms of their applicability to the LEAP framework, and discusses the principal determinants of conventional domestic ofl and gas supply in the long run. 
CONTENTS

Abstract..............................................

Introduction $\ldots \ldots \ldots \ldots \ldots \ldots \ldots \ldots \ldots \ldots \ldots \ldots \ldots \ldots \ldots \ldots \ldots \ldots \ldots$

The Long-term Energy Analysis Package Framework............... 1

Approach to Long-run $0 i 1$ and Gas Supply Curves................ 3

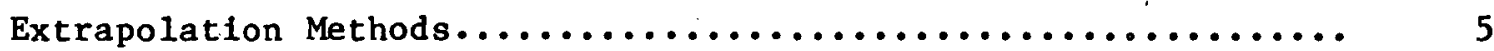

Econometric Models................................ 8

Discovery Process Models............................ 11

Comparison of Historic Projections........................ 1s

Conclusion.$\ldots \ldots \ldots \ldots \ldots \ldots \ldots \ldots \ldots \ldots \ldots \ldots \ldots \ldots \ldots \ldots \ldots \ldots \ldots \ldots$

References.......................................... 19 
The following is a report on the literature review subtask of the LongRange Forecasting Methodology for 011 and Gas Supply project being performed at Brookhaven National Laboratory for the Division of 011 and Gas Analysis (OGA) of the Energy Information Administration. The purpose of the study is to provide OGA with the capability to project conventional domestic oil and gas supply possibilities at least 40 years into the future. The projection methodology must be compatible with the Long-Term Energy Analysis Program (LEAP). This report analyzes the principal determinants of oil and gas supply in the long run and evaluates the methodologies identified through the literature survey in terms of their compatibility with the LEAP framework.

The report begins by providing an overview of the LEAP resource submodel framework and indicating the characteristics that the projection methodology must possess.

THE LONG-TERM ENERGY ANALYSIS PACKAGE FRAMEWORK

The Long-term Energy Analysis Program (LEAP) equilibrates supply and demand over a time horizon of 50 years. It represents the economy/energy system as a network of energy flows leading from primary resources to end-use demands. Resources in each region are extracted, processed, and transported, either directly to the consumer or to another processor such as a power plant. At each stage, the impacts of input prices on the product price make themselves felt. Finally, the consumer's demands change in response to prices.

LEAP uses an iterative scheme to arrive at price/quantity equilibrium. Consumer demands imply quantities that must be output from each process in the network. For each process, the product price is calculated on the basis of these demands. If consumer demands remain the same at the newly computed prices, equilibrium has been reached. Otherwise a subsequent iteration is performed.

Within the LEAP framework, the resource submodel, at the "bottom" of the network, accepts quantities as inputs and outputs the prices required to bring forth those quantities. The time horizon is divided into ten periods of five years each. Each regional submodel is given the (reglonal) demand for each time period; LEAP generates the schedule of demands endogenously. The regionalization scheme may be resource specific. 
The price computation depends on these factors:

- investment in exploration and development,

- production costs,

- effects of technological advances on capital and operating costs,

- foresight of future prices.

Level of depletion, also referred to as cumulative commitments, is determined by calculating forward in time the new reserves that must be added in each time period to meet the production schedule implied by the demands. Reserve additions are then translated to cumulative commitment level in each time period. Implicit here is the assumption that reserves having the lowest minimum acceptable price will be discovered and produced first.

Cumulative commitments are related to minimum acceptable price by an exogenous supply curve. A parallel supply curve contains the capital cost component of minimum acceptable price at each cumulative commitment level. If appropriate, the capital and operating costs may be modified by a learning curve that the LEAP user inputs. The curve indicates how costs will change over time because of technological advances (that are not incorporated in the assumptions underlying the exogenous supply curves). Given these parameters, the resource submodel calculates the price in each time period; these prices differ from the learning-curve-modifled minimum acceptable prices by a quantity known as the rent.

The rent is derived from foresight (which may be perfect or imperfect to varying degrees) of future prices. The resource submodel calculates the present value of revenue that would be obtained if production from a new reserve addition were delayed one or more time periods. If benefit could be gained from waiting, the assumption is that the resource producer must recelve a bonus to make immediate production equally attractive. This bonus is the rent.

This formulation has been criticized on the grounds that lease agreements may preclude production delays: Another problem is that the producer, as represented in the LEAP resource submodel, foresees only his own future minimum acceptable prices. Rent in one region is unaffected by prices in another. Nor do the world oil or gas prices enter directly into the calculation, although the LEAP 1teration scheme guarantees that allocation of demands between domestic sources and imports eventually attains equilibrium. However, regional and import prices need not be equal in the converged solution.

With the problem of rent in mind, a literature survey of ofl and gas supply projection methodologies was undertaken. The purpose of the survey was to identify approaches to handling the determinants of conventional domestic oil and gas supply in the long run, and to see how they might be applied to the generation of the long-run supply curves required by LEAP, namely, those relating cumulative commitments to minimum acceptable price/capital cost component. 
The principal determinants of conventional domestic ofl and gas supply in the long run are: (a) how much is as yet undiscovered or discovered and economlcally submarginal, and (b) how much it will cost to find and produce these resources. It should be stressed at the outset that estimates of undiscovered oil and gas resource estimates have profound political implications. The conflicts of interest are such that it is unlikely that any estimate or methodology will enjoy wide acceptance. Wildavsky et a1.44 provide a stimulating discussion of reasons for this in a paper on the history and philosophy of oil and gas estimation.

Resources may be classified, following McKelvey, 24 as recoverable/ identified, subeconomic/identified, recoverable/unidentified, subeconomic/ unidentified. Within the known resource category, finer distinctions may be made (see Figure 1) relating to the degree of uncertainty in the estimate of resource magnitude, or the margin by which exploiting the resource fails to be economic.

Identified

Undiscovered

\begin{tabular}{|l|l|l|}
\hline Proved & Probable & Possible \\
& \\
\hline Paramarginal Resources \\
(recoverable with 50\% \\
price increase) \\
Submarginal Resources \\
(greater than 50\% \\
price increase required)
\end{tabular}

\author{
Figure 1 \\ "McKelvey Box" (modified)
}

This scheme for resource classification shows variations in certainty of rcsource cxietence and in economiss of resnvery, The diagram does not portray relative magnitudes of resources in the different categories. 
In the long term, it seems reasonable to assume that all domestic oil and gas reserves currently 1dentifled will be produced. Present reserves of oil amount to only about 27.8 billion barre1s,* which will last about nine years at the present consumption rate of 30 billion bbl/yr. Similarly, reserves of gas are estimated at 200.3 trillion cubic feet, enough for 10 years at the present consumption rate of $20 \mathrm{trillion} \mathrm{ft}^{3} / \mathrm{yr}$. (Maintaining oil and gas production at current levels would for technical reasons, not be possible unless new reserves are found; in fact, "An analysis by Atlantic Richfleld shows that nearly half of the country's 1990 oil production must come from future discoveries."*) Known reserves, therefore, can almost certainly not meet domestic demand, which, in the case of oil, is now approximately double domestic production, over a 40-year time horizon. It follows that long-term supply projections must rely on estimates of undiscovered and of discovered but subeconomic resources.

Cook ${ }^{5}$ makes the point that the amounts of reserves and motential reserves depend on cconomic as well as geulugle paramecers. The cost of possible substicutes, govejernment regulations and taxes, and technological advances are all factors in determining the economically recoverahle resource base. As sear $1^{35}$ and stitt 40 note, not all "dry holes" fall to contain hydrocarbons: in some cases the find is simply not worth exploiting at present prices. Eckbo et a1.9 show that the minimum economic reservoir size can be computed on the basis of price projections and cost information. Presumably a discovery below this size would be classified as a "dry hole" and abandoned. Rising prices in the future might alter the picture. (It is interesting to speculate on how much of the recent substantial increase in developmental drilling reflects decisions to produce from what were formerly considered "dry holes.") Very few methodologies address the question of the subeconomic resource base.

The methodologies for inferring the amount of undiscovered resources fall generally into three categoilies: extrapolation, econometric models, and models of the discovery process.

Using extrapolation methods, one fits a curve to data on production vs. t1me or reserve additions vs. drilling. It is implicitly assumed that the economic forces at work in the past will continue to exert the same influence in the future. Prices are not explicitly considered, and this makes policy analysis impossible,

\footnotetext{
*American Ketroleum Institute (API) special report, U.S. petroleum industry will face monumental task in next decade, 011 and Gas J. 77 (46), 174-84 (Nov. 12, 1979).
} 
Econometric models generally take prices as input, and calculate production. Most do not incorporate physical limits to ultimate production, which would almost certainly lead to unrealistic results in a long-term model: domestic sources of oil and gas are commonly expectd to become exhausted in the LEAP time frame. The main problem with using such a model in the LEAP framework is that it would be difficult to calculate price as a function of quantity demanded.

Discovery process models relate drilling activity to reserve additions. Given the costs of drilling, discounted cash flow analysis is used to compute minimum economic reservoir size, minimum acceptable price, or, if prices are known, the rate of return. This approach is the one most compatible with the LEAP framework, since quantities immediately imply prices, and policy analysis can readily be performed.

A fuller discussion of the three approaches follows in which selected models from the literature are evaluated in terms of what they might offer the LEAP resource submodel. Included in the section on econometric models are some investigations into the theory of exhaustible resources, and other approaches which touch on the question of rent.

Extrapolation Methods

To this category belong the growth curves of M.K. Hubbert,15,17 which have generated a great deal of controversy (e.g., Ryan, 32,33 singer, 37 Hubbert ${ }^{16}$ ). Hubbert 15,17 fits a logistic curve to data on cumulative discoveries of oil in order to arrive at an estimate of ultimate domestic recovery. The logistic curve has the form

$$
y(t)=k /\left[1+a * e^{-b *\left(t-t_{0}\right)}\right]
$$

where $y$ is cumulative discoveries, $a, b$, and $k$ are constants, $t$ is time, and $t_{0}$ is a reference time (Hubbert takes $t_{0}=1900$ ). This functional form has been used to describe population growth; $k^{i}$ represents the limit. Since the logistic distribution function is

$$
F(t)=\left[1+\exp \left(-\alpha_{\star} t-\beta\right)\right] \quad \alpha>0
$$

(Feller, 12 p. 52) it follows that in Eq. (1) a >0, b > 0, and, since cumulative recoveries are positive, $k>0$. The logistic function is derived from the assumption that the percentage rate of growth is proportional to the difference between the ultimate population limit and the current population size:

$$
y^{\prime}(t) / y(t)=b *[k-y(t)]
$$


This is also equivalent to

$$
\frac{d}{d t} \ln y(t)=b *[k-y(t)] \text {, }
$$

that is, the rate of change in the $10 \mathrm{~g}$ of cumulative discoveries is proportional to the amount undiscovered.

Another functional form favored for projections is the Gompertz curve,

$$
p(t)=a * b^{c t} \text {, }
$$

which Moore 28,29 uses to represent cumulative production $p(t)$. Curve fitting as a means ot projection can be (and has been) criticized on at least the following grounds:

- Economic forces are not considered.

- The particular functional form cannot be justified on physical grounds, and many other forms offer equal or better goodness of fir to observed data.

- Potential technological advances cannot be modeled.

- Discoveries depend on time rather than exploratory effort.

Hubbert ${ }^{17}$ deals with this last criticism by considering oil discovered as a function of exploratory drilling, and arrives at the same estimate for ultimate recovery as he had obtained previously. Although the objections to the curve fitting methods remain unrefuted, these techniques have not fallen into disuse, at least partly because of their success in predicting what has come to pass (see, e.g., Deffeyes and MacGregor, ${ }^{6}$ p. 70), and also because of the comparative ease with which such analysis may be performed. Thus, two recent studies employ curve fitting to forecast the number of undiscovered giant oil fields 27 and total undiscovered oil resources. 41

Curve fitting approaches have also been applfed to the problems of determining the number and size distribution of undiscovered resource "pools" in a given region. Slichter ${ }^{38}$ considers the areal distribution of ore bodies. Previous work had suggested that the poisson distribution provided a good fit to the number of mines found per unit area. This runs counter to the commonly held belief that exploration is more likely to be successful near known resources than in territory where no resources have been found. Slichter's data for ore bodies show a far better fit to the exponential distribution. However, this is unlikely to be the "true" underlying distribution since one of its properties is that the chance of future discoveries is unaffected by the number that have already been made. 
Slichter also investigates the distribution of the values/sizes of ore bodies discovered, and finds that these appear to follow the lognormal distribution, a conclusion reached by DeGeoffroy and $\mathrm{Wu}^{7}$ as well. This implies that a few large ore bodies will be immensely valuable. This also appears to be true of oll and gas finds, as is shown in a number of later papers. Momper 27 considers "glant fields" so important that he claims an accurate projection of their number would allow "reasonably" accurate projection of remaining und iscovered oil.

Kaufman 18 argues that the distribution of pool size within a play, or group of simflar geological configurations, is lognormal, and advances physical reasons why this might be so: chemical reactions depend on the concentrations of the reagents involved. Assuming that the probability of finding a particular pool is proportional to its size (as compared with all other undiscovered pools within the play), one can infer that the average size of a new discovery will decrease as more of the resource base is explored ${ }^{19}$ or estimate recoverable ofl in a play.1 Griffiths' datal3 also support the assumption of lognormal sizes.

Simflar concord has not been reached on the number of mines or pools within an area. Griffiths, 13 in studying the number of wells per unit area in Kansas, concludes that the negative binomial provided the best fit, especially when compared with the Poisson, omitting the "exceptionally large Hugoton Gas Field." DeGeoffroy and $\mathrm{Wu}^{7}$ also choose this distribution: "Because the outcome of the search for commercial deposits is either a success or a failure and because of the large variance of the data (four times the value of the mean), a negative binomial distribution is used as a theoretical model." However, success or failure is not that clear-cut: an uneconomic well may become commercially exploitable. Moreover the independence assumptions underlying the exponential, Poisson, and negative binomial distributions do nct seem appropriate for exploration, since knowledge about the resource base is gained in the process. Ryckborst 34 comments on problems with the "independent trial" assumption; he prefers Pearson frequency analysis for predicting oll-in-place found as a function of exploratory "trials."

Two other extrapolation approaches that have been popular are the volumetric and subjective probability methods, which make far less use of available historic data than dn curve fitting techniques, In volumetric methods, the potential of untested areas is estimated by extrapolation based on experience with known areas having similar characteristics. Here the weak point is the lack of basis for selecting the factor relating volumes of resources in untested sediments to discoveries in known areas.43 Subjective probability techniques were employed by the U.S. Geological Survey to estimate undiscovered oil and gas reserves. 25 "Expert judgment" is difficult to argue with, and also difficult to defend; Kaufman 19 mentions some of the pitfalls.

Extrapolation methods are not compatible with the LEAP framework because they do not associate prices with reserve additions. Moreover, some consider estimates of undiscovered resources or ultimate production to be meaningless in the absence of economic considerations. 35 
If extrapolation methods focus on quantities to the exclusion of prices, econometric models focus on prices, sometimes to the exclusion of physical considerations. Khazzoom's econometric model 20 estimates discoveries as a function of time-lagged prices; there is no limit to the amount of resource that may be discovered. New discoveries are positively related to discoveries in the previous two years; the only negative influence on new discoveries (apart from the intercept) is possibly the price of oil, since this may result in diversion of effort from finding gas. Such a formulation may be appropriate for short-term analysis, but it does not incorporate factors that will become increasingly important in the LEAP time frame. The finiteness of the resource and the prospects of exhaustion will influence the price. Cook ${ }^{5}$ argues that supply becomes inelastic as natural gas in conventional reservoirs becomes depleted. He also observes that future costs of substitutes and the interaction between price and demand will bear heavily on undiscovered resource estimates. Other crucial uncertaintles have to do with technolnglcal. evolution over tlme, as unforeseen advances may lower extraction costs or result in improved methods for evaluating geological prospects.

Like other econometric models, Khazzoom's relies on price, or, equivalently, cash flow, as an explanatory variable. MacAvoy and Pindyck's wellknown econometric model 23 of natural gas markets, for example, relates prices, costs, drilling, and discoveries by linear equations whose coeffictents are estimated with historic data. The model includes relationships between total exploratory well drilling, cash flow, average total drilling costs, and risk (defined as the variance in payoff size), slze of discoveries per well, dril1ing costs, and number of wells. These equations also include variables representing regional differences. It is found that the number of wells increases with cash flow, and decreases with cost and variance in payoff size. The discovery size decreases with the number of wells, an anticipated depletion effect. The model was used to study effects of government policies, such as deregulation.

Epple ${ }^{10}$ reviews the MacAvoy-Pindyck work and other models preceding it. He goes on to discuss the theory of exhaustible resource supply. He concludes (p. 65),

"First, at the optimal production rate, price no longer equals marginal production cost. Marginal cost may be defined to include the opportunity cost of foregoing production of the good in a subsequent period. Price then equals marginal production cost plus marginal opportunity cost. Second, production in any period is dependent not only on current price and cost conditions, but on expected future prices, costs, and discount rates. Th1rd, there is no supply curve reproducible or otherwise. A number of supply curves can be derived in any period by postulating a different pattern for prices in the future. Finally, 
market equilibrium is characterized not by a point in price-quantity space, but by prices and quantities which are functions of time and clear the market for the resource up to the time that exhaustion occurs."

Epple goes on to formulate an econometric model in which:

- There is an aggregate supply function for "oil-bearing land."

- The objective function of the exploration firm, which depends on aggregate supply of oil-bearing land and unit rent for it, is maximized subject to the constraints of the production function, and is linear in feet drilled.

- The production function has the "constant elasticity of transformation" form.

Epple concedes that "Neither the price, $R$, nor the quantity, L, of oil-bearing land is observable," and these variables are eliminated through algebraic manipulation. However, he is left with a parameter representing the elasticity of supply of oil-bearing land, for which he cannot obtain a statistically significant estimate, and which exerts a great deal of influence on the behavior of the supply equation.

The theory of exhaustible resources has also been explored by Solow and Wan, 39 who attempt to solve the societal problem of finding the "largest permanently sustainable level of consumption." The resource flow is "indispensable to production, but there is no limit to the output that can be produced from a given flow of resource input, if only there are enough labor and capital available." This rather strange conclusion is the result of the choice of the Cobb-Douglas form for the production function, which makes pussible sustained consumption for an infinite time. Other questionable assumptions are that population remains constant and that demand is not influenced by the extraction price.

Hea1 14 takes another approach to the problem, considering an exhaustible resource the price/cost for which is limited by the availability of an inexhaustible "backstop technology." He investigates the difference between the price of the extracted resource and the marginal extraction cost. This difference, a royalty or rent, has been thought to grow exponentially, at the discount rate, but in Heal's formulation, it goes to zero. The reason for this is his assumption that an infinite amount of the resource becomes avallable at the backstop technology price. The royalty or rent in Heal's model reflects the extent to which future costs of extraction are increased by present extraction activity; when the backstop technology comes into play, a11 future extraction has the same cost. Heal's discussion of rent is particularly interesting because of its similarities to rent computations in LEAP. 
Pindyck 30 also addresses the question of production of exhaustible resources. In his derivation, optimal paths of exploration, production, and price depend "critically" on the intial level of proved reserves.

Large initial reserve levels imply that exploration will be postponed, whereas small ones encourage exploration. The driving force behind this appears to be the assumption that the cost of production is a decreasing function of proved reserves; as proved reserves decline to zero, the production cost becomes infinitely large. This assumption seems too simple: production costs might instead increase with new reserve adiltions, depending on the technical characteristics of the reserves. Another problem is that Pindyck is investigating the optimal strategies of exploration and production; it is not clear that real-world producer behavior will follow such a pattern. Forexample, the conclusion drawn from one equation is, "each producer should produce either nothing or at some maximum capacity level." While a producer might withhold some supplies, producing nothing is unlikely to be a real option.

Pindyck discusses rent, and concludes that, "if extraction costs rise rapidly enough as depletion occurs, rent can fall over time. This simply implies, however, that the opportunity cost of resource extraction is falling because resource use is decreasing as extraction costs (and therefore price) rise, so that in an in situ context the resource is indeed becoming less scarce."

The producer of the resource can be thought of as facing an intertemporal allocation problem. More generally, society must consider the consequences of patterns of resource use. Modiano 26 explores normative models for non-renewable resources. The optimal behaviors of the supplier and the consuming economic sector are studiea through decomposition methods. The supplier maximizes present value of profits resulting from a production schedule over a planning horizon. (A salvage function embodies the value of resources remaining at the end of the horizon.) The economic sector calculates its costs under an assumed resource production schedule. If savings would be achieved by greater supply, the economic sector induces greater production through increased prices. Iteration on price and quantity equilibrates demand and supply. Modiano considers the effects of uncertainty in end-use demands, and suggests that the supplier's willingness to meet demands "here-and-now" results in lower revenue than a walt-and-see policy.

The models discussed in this section afford good intultive insights into the problems of predicting oil and gas supply, and into the dilemas of the supplier and consumer of non-renewable resources. However, such wiodels do not appear to be comparible with Llie LEAF resource submodcl framework in which quantities must be input and prices output. The economic models take prices as input, and yield quantities produced; the inverse of the function may not be readily obtained. This difficulty is illustrated by Uri's hybrid approach 42 which combines curve fitting and econometric techniques. The functional form is

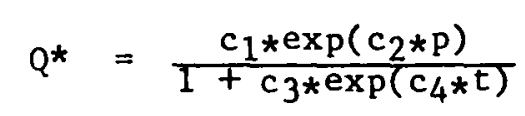


where $p$ is the price of crude, $t$ is time, $Q^{*}$ is the quantity of ultimately recoverable resources, and the parameters $c_{1}, c_{2}, c_{3}, c_{4}$ are estimated with historical data. The price required to induce given commitment levels in a time period cannot be predicted with this equation.

The methods used for resource base projection fail to consider economic aspects explicitly, which makes them poor tools for policy analysis even though their projections have been fairly accurate. 5 Econometric models, which have not enjoyed the same success, often fall to incorporate physical considerations. The best solution would appear to be to combine the two approaches, as suggested by Barouch and Kaufman.2 Hybrid approaches, which incorporate economic and geological/geophysical parameters, are generally classified as discovery process models. Examples include the Midterm $0 i 1$ and Gas Supply Modeling System (MOGSMS), 11 the model developed by Kim and Thompson, 21 the LORENDAS framework, 31 and the AGA TERA model reviewed by Ciliano, Limaye, and Hu. ${ }^{3}$ (Ciliano, Fallah, and Limaye ${ }^{4}$ also review some of these approaches in a study of ofl supply modeling.)

Discovery Process Models

In discovery process models, minimum acceptable prices and reserve additions are functions, usually deterministic, of driling activity. Minimum acceptable prices are found through discounted cash flow analysis, where the cost per foot drilled is the basic variable. Other expenses, such as geological and geophysical exploration expenses, are proportional to drilling cost. Taxes, investment credits, interest, royalties, and so on, may be included in: detail, so that the effects of government policy changes can be represented.

The relationship between feet drilled, $d$, and reserve additions, $R(X, d)$, is expressed by a finding rate function, $F$, where $X$ is cumulative feet drilled:

$$
R(X, d)=\int_{0}^{d} F(X+h) d h .
$$

By letting $d$ go to infinity, one obtains total ultimately recoverable resources. This implies that $F$ must go to zero; the models mentioned have finding rate functions that are monotonically decreasing as well. Embedded in these discovery process models, then, are estimates of undiscovered resources. One infers, therefore, that the discovery process model relies on curve fitting just as hcavily ae any of the surve fitting extrapolation methods. 
Fitting a functional form to finding rate data has posed many difficulties for modelers. As Ciliano et al. ${ }^{3}$ (p. III-117) put it, "In TERA as with almost every comprehensive model of gas supply, the task of deriving either finding rate or average discovery size relationships from empirical data and available estimates of the recoverable resource base remains the most difficult problem to overcome and one which severely compromises the predictive power of these methodologies."

The problem is that the historic behavior of the finding rate does not lend itself to smooth curve fitting. Stitt 40 plots cumulative reserve additions against cumulative successful oil footage, and observes that the rate of 38 barrels per foot drops abruptly to 17.5 in 1974. This of course coincides with a major discontinuity in world oil prices and other radical changes affecting the industry. A number of hypotheses have been advanced to account for this. Unfortunately, Stitt concludes, some of the most promising cannot be tested because the data are not publically avallable.

Seidl36 tries the approach of plotting cumulative reserves against culuulative wells drilled. He finds that reserve additions per well have "... stayed pretty much constant during all these years [1960-1974], if we allow for the retarded announcement of the Alaskan discoveries, at about 95,000 barrels/ well" (Seidl,36 p. 125). His data on wells drilled vs. cost per well show an interesting pattern which seems to support the hypothesis that after this oil embargo, developmental drilling connected with known, previously subeconomic deposits, and "drilling for rate" caused the apparent drop in reserves added per foot drilled. The number of wells drilled declines in linear fashion with the increasing cost per well from 1960 through 1973. The 1974 point (data are "lagged by one year") is a marked outlier: the number of wells increases by about 37.5 percent from the 1973 figure while the cost per well, in barrels of oil equivalent, falls by about 35 percent (Seidl, 36 p. 127).

One way of dealing with such discontinuities is to fit the finding rate curve only through 1974. This is the approach adopted by Kim and Thompson, 21 who find a good fit to gas and oil finding rate curves of the form

$$
\left(\log \mathrm{F}_{0}-\mathrm{b}_{0}\right)^{2}=\mathrm{b}_{1}+\mathrm{b}_{2} \log \mathrm{x}_{\mathrm{o}}
$$

where $F_{O}$ is cumulative discoveries, $X_{0}$ is cumulative exploratory drilling footage, and $b_{0}, b_{1}, b_{2}$ are estimated through regression. Since $b_{2}$ is positive, one can see that $F_{0}$ goes to infinity as $x_{0}$ goes to infinity. This cannot be right, no matter how significant the t-statistiss.

Another problem with the finding rate is that the extent of a discovery is not known imrediately. Reserves may be inferred or indicated. Both the Kim and Thompson model and MOGSMS use Hubbert factors to represent growth in a deposit as more knowledge ahout it is gatned; TERA has a similar growth schedule. 
The finding rate specification in most discovery process models is deterministic. An exception is the approach of Eckbo et al., 9 which is to a large extent based on earlier work by Kaufman 18 and by Barouch and Kaufman. 1 Under the assumptions discussed earlier on reservoir size and discovery probabilities, one can make maximum likelihood estimates of the number of pools in the play and the parameters of the lognormal distribution, given the sizes of the first $n$ discoveries. Since the estimates improve as more discoveries are made, so the approach hardly seems applicable to unknown areas. Moreover, the U.S. might have to be partitioned into a large number of plays in order to obtain good results.

However, some means of incorporating probabilistic elements, or surprises, seems desirable. The possibility of further giant field discoveries in the U.S. cannot be ruled out, particularly in view of new exploration technology. 27 Excepting the Eckbo/Kaufman approach, discovery models do not allow for such events.

In addition to having problems with finding a good functional form for the finding rate, modelers using feet drilled as the independent, or explanatory, variable have difficulties with drilling patterns, directionality, and constraints on the feet drilled. Drilling patterns have been touched on above: the producer must decide whether to drill exploratory wells; drill "for rate," i.e., increase the production-to-reserves ratio; drill test wells in connection with a known deposit, which may lead to extensions or revisions; or drill to develop a previously discovered but unexploited pool. Unfortunately, data are not collected in this detail, although aggregate figures for total footage, wildcat footage, and well completions are available. The discovery process models tend to ignore developmental drilling. MOGSMS for instance does not consider developmental drilling explicitly; the implicit assumptions are that a deposit will be developed through the secondary recovery phase, and that such drilling footage is not subject to constraints. LORENDAS does contain such constraints, exogenously specified; how they are arrived at is not clear. Though the discovery process models focus on exploratory drilling, wildcat footage in 1979 was only $28,372,451$ out of total footage of $112,081,944$.*

Another unknown aspect of the drilling decision is directionality. While wells are classified as oil or gas producers (oil wells may have associated gas), the objective of the exploration, or directionality of the drilling, is unknown. For this reason it is difficult to allocace dry hole foutage to exploratory gas or oil drilling; such an allocation is ususally made in fitting the finding rate curve. Presumably geological/geophysical indications give the producer clues as to which type of hydrocarbons a prospect will contain; the relative prices of oil and gas may dictate which kind of prospects are explored first. Kim and Thompson 21 develop a "split" factor, which they find to be highly correlated with a relative profitability index. The ratio of current net revenue from an oil discovery, to total project cost, is divided by the corresponding ratio for a gas discovery. Clearly, prices must be known in advance to make this calculation, which presents a difficulty in the LEAP framework, but the approach seems reasonable. Similarity, the AGA TERA model has a risk index that relates profitability to number of wildcat wells.

*il Gas J. 77, (33) 150 (Aug. 13, 1979). Cumulative footage for year through June. 
Constraints on drilling levels are troublesome. The problem is that while there are practical limits to drilling footage, but it is not clear how to set them in a model; in any case, the LEAP framework does not lend itself readily to the imposition of constraints. Because the U.S. petroleum industry is multinational, domestic projects must compete with worldwide development opportunities. In 1979, half the industry's total program was earmarked for these.* Since rigs are mobile and can be moved from one region to another, or abroad, it is difficult to determine a reasonable way of setting constraints on drilling. One possibility is to relate footage to the industry's capital expenditures budget; this in turn would depend on profits, prices, and costs in the previous time perlod. LORENDAS allows only a certain rate of growth in exploratory drilling from one time period to the next. MOGSMS determines the extent of the resource base that will be economically feasible to explore, and allocates the implied drilling footage over time so that rig capacity is fully utilized and minimum acceptable prices in each region are eventually equalized to perform this calculation, prices must be known. KIm and Thompson 21 have a normative submodel of producer behavior, maximizing profits subject to constraints on expansion, and requiring full utilization of capactey over time.

Aside from the finding rate curve and drilling footage limitations, the physical parameter of most importance in discovery process models is the production to reserves ratio or decline rate. Usually the production schedule is specified in terms of a fixed fraction of reserves being produced each year. The decline rate bears on both the timing of resource comnitments and the economics of exploration. As the decline rate increases, resource commitments can be delayed because more can be obtalned from present reserves. Accuracy in predicting the decline rate is vital in the short term: with proved reserves of 27.8 billion barrels, the difference between domestic production at a 12 percent decline rate and at a 10 percent decline rate is over 1.5 million barrels per day. With higher production in the earlier years, net present revenues also increase, making minimum acceptable price lower. Decline rates have not remained constant over time (Stitt, 40 p. 26) and can be altered to some extent through developmental drilling. However, the relationship between economics, regulation, and the decline rate has not been explored in the literature, and pending further research, assuming a constant decline rate seems acceptable in a long-run model.

*011 Gas J., 77, (8) 62 (Feb. 19, 1979). 
Above, the three main approaches to oll and gas supply curves have been examined in terms of their compatibility with the LEAP framework. It is also instructive to compare the historic performance of these methods with respect to their success in projecting what has come to pass, since not only compatibility with LEAP but validity of the approach must be criteria in developing a forecasting methodology.

Figure 2 shows several natural gas production projections that were made between 1972 and 1974; the data points are reported in Table 1. The IGT (Institute of Gas Technology) and IEA (Institute for Energy Analysis) projections are based on curve fitting methods; the $\mathrm{H}-\mathrm{J}$ (Hudson-Jorgenson) and $\mathrm{M}-\mathrm{P}$ (MacAvoy-Pindyck) models are econometric; the NPC (National Petroleum Council) and PI (Project Independence) projections come from discovery process models. Historic data, as pub1ished by the Energy Information Administration* are shown as dots, while curves connecting the points from other projections are sketched in. Where alternative projections were made, the ones characterized as most reasonable by the authors were plotted. In the absence of such characterization, the forecast that has turned out to be most correct or forecasts bracketing the historic trends were chosen.

The IGT model of Lower-48 natural gas supply is described as "a useful forecasting tool in the absence of radical changes in the economic and regulatory climate, and in production technology." Historical data are correlated and trends are projected on that basis. (Linden, H.R., An Analysis of Potential Production of Natural Gas in the United States, Institute of Gas Technology, Chicago, IL, 1972.) The IEA model uses $\log$ istic curves; the points shown are based on ultimately recoverable natural gas (excluding liquids) of 1000 Tcf. Hubbert (Ref. 17, p. 135) considers 1050 Tcf most reasonable. (Whittle, C.E. and Reister, D.B., The IEA Energy Simulation Model, The Institute for Energy Analysis, Oak Ridge Associated Universities, Oak Ridge, TN, Jan. 1975, see pp. 65-9.) The Hudson-Jorgenson projections "are based on the assumption that there are no major changes in energy policy, either by the U.S. or foreign governments, over the forecast period." [Hudson, E.A. and Jorgenson, D.W., U.S. energy policy and economic growth, 1975-2000, Bel1 J. Economics and Management Sci. 5 (2), 461-514 (1974).] Similariy, the MacAvoy-Pindyck forecast assumes "regulatory status quo" (Ref. 23, p. 492). Both the NPC and PI forecasts rely on discovery process models that evolved into the Energy Information Administration's Midterm 011 and Gas Supply Mode1ing System. The NPC numbers are "Intermediate appraisal" and a pessimistic view that environmental issues, government policles and lack of improvement in finding rates would hold down supply. (National Petroleum Council, U.S. Energy Outlook, A Report of the Natlunal Petroloum Connril's Committee on Energy Outlook, Washington, $\mathrm{DC}, \overline{\text { Dec. 1972, see pp. 5, 18-9.) The Project }}$

*The points for 1965-1978 are from the marketed (domestic) production figures in the Annual Report to Congress 1978, Volume II: Data. Energy Information Administration, Washington, DC, DOE/EIA-0173/2. The 1979 figure is from the Monthly Energy Review, Energy Information Administration, Washington, DC, DOE/EIA 0035/02(80) Feb. 1980. 
Independence figures reflect a "business-as-usual" (BAU) case with the then current regulatory environment persisting, and an accelerated development case (ACC) with greater drilling escalation and increased price incentives. (Federal Energy Administration, Task force report--natural gas, in Project Independence Blueprint, Washington, DC, Nov. 1974, see pp. 111, xili, xv, III-9.)

As can be seen from Figure 2 and Table 1 , the discovery process models have done better than the econometric or curve fitting approaches. This may be attributed to the flexibility of the discovery process approach which does not force one to assume that historic trends will continue; the other approaches require this assumption.

Figure 2 represents an updating and modification of a figure that originally appeared in a 1975 report by Langlols, 22 in which historic data through 1.473 were plotted. At the tlwe, Langlols observed that the Project Independence Evaluation System (PI) forecasts came closest to actual behavior. This observation remains true. In 1975, Janglois wrote,

\begin{abstract}
"Furtherwore, the qualitative behavior of the PI projections is reasonable if one admits the current thinking in FPC [Federal Power Commission] and industry writings: the present slump is the result of government price controls which keep the market value of gas artifically below that of alternative fuels."
\end{abstract}

It appears that the Project Independence Evaluation System was capable of handling these considerations.

\title{
CONCLUSION
}

All three of the approaches, curve-fitting, econometric, and discovery process, have something to offer the LEAP resource submodel framework. of the three, the discovery process approach appears to best suited for adaptation to LEAP. The economics and politics of resource production must be adequately represented if the forecasting merhndnlogy ie to yicld reallulle resulis; the system must be sufficiently flexible to incorporate a variety of assumptions. Discovery process models incorporate both physlcal and cconomic parameters and can respond realistically to changes in political and ernnomic conditions such as varlous government regulatory policles, tax laws, and price trajectories. The political environment with respect to resource exploration and development has been relatively unstable for the past eight years; the position that past trends are good predictors or the future is no longer tenable. Discovery process models appear to have the most to offer as oll and gas oupply forecasting methodologies. 


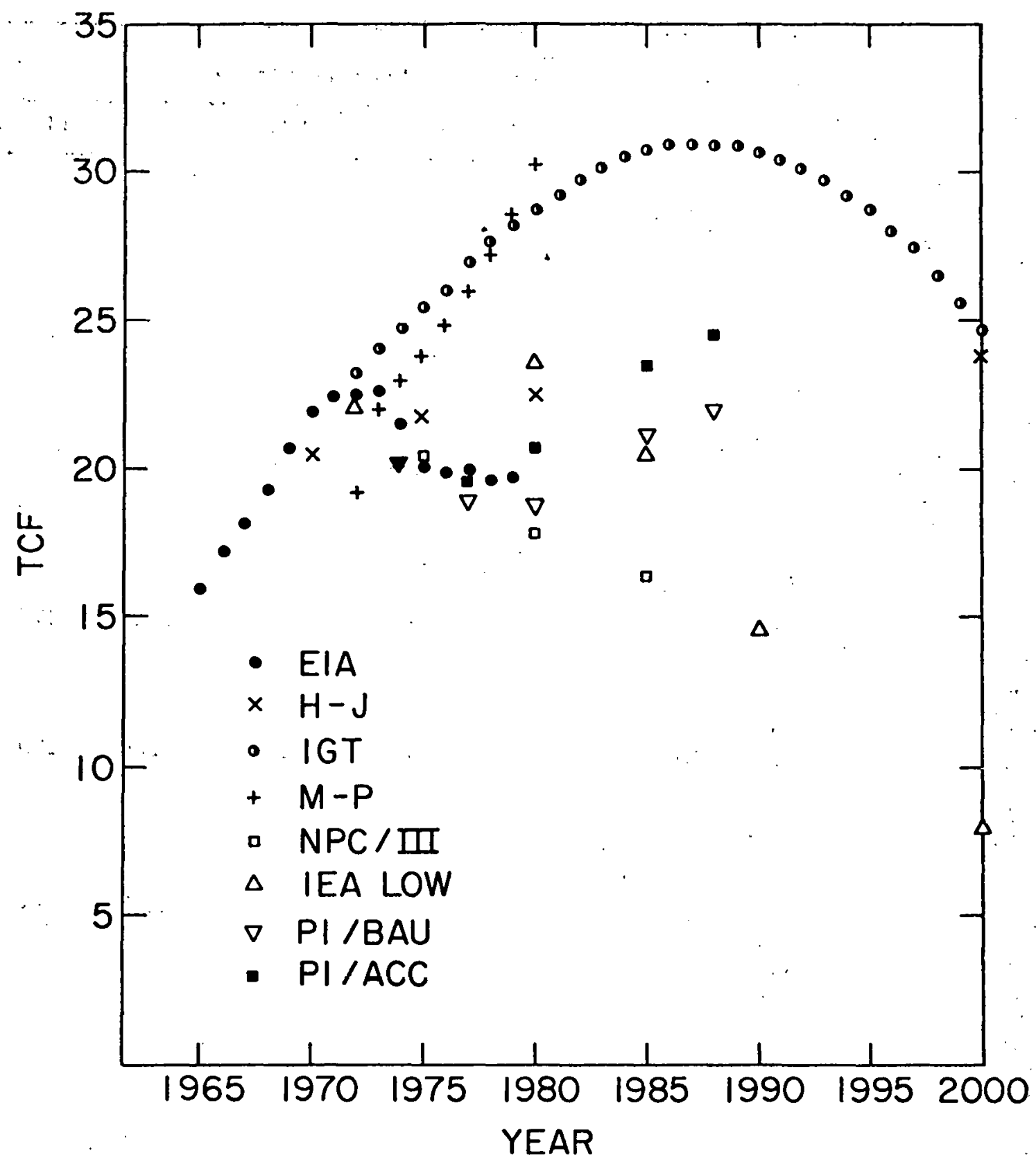

Figure 2

Historic National Natural Gas Production 


\section{Table 1}

Natural Gas Production Projections and Historic Data, Tcf

\begin{tabular}{|c|c|c|c|c|c|c|c|c|c|}
\hline Year & Historic & IGT & IEA & HJ & $\mathbf{M P}$ & NPCIII & NPCIV & PI/BAU & PI/ACC \\
\hline $\begin{array}{l}1965 \\
1966 \\
1967 \\
1968 \\
1969\end{array}$ & $\begin{array}{l}16.04 \\
17.21 \\
18.17 \\
19.32 \\
20.70\end{array}$ & . & ${ }^{\circ}$ & . & * & & & . & \\
\hline $\begin{array}{l}1970 \\
1971 \\
1972 \\
1973\end{array}$ & $\begin{array}{l}21.92 \\
22.49 \\
22.53 \\
27.65\end{array}$ & $\begin{array}{l}23.2 \\
24.0\end{array}$ & 22.1 & $\begin{array}{c}20.6 \\
.\end{array}$ & $\begin{array}{l}19.2 \\
22.1\end{array}$ & & . & & . \\
\hline $\begin{array}{l}1974 \\
1975 \\
1976\end{array}$ & $\begin{array}{l}21.60 \\
20.11 \\
19.95\end{array}$ & $\begin{array}{l}24.8 \\
25.6 \\
26.3\end{array}$ & & 21.8 & $\begin{array}{l}23.0 \\
23.9 \\
24.9\end{array}$ & 22.0 & 21.8 & 20.2 & 20.2 \\
\hline $\begin{array}{l}1977 \\
1978 \\
1979\end{array}$ & $\begin{array}{l}20.03 \\
19.69 \\
19.72\end{array}$ & $\begin{array}{l}27.0 \\
27.7 \\
28.3\end{array}$ & $\cdot$ & & $\begin{array}{l}26.0 \\
27.2 \\
28.6\end{array}$ & & & 19.0 & 19.6 \\
\hline $\begin{array}{l}1980 \\
1981 \\
1982 \\
1983 \\
1984\end{array}$ & . & $\begin{array}{l}28.8 \\
29.3 \\
29.8 \\
30.1 \\
30.5\end{array}$ & 23.8 & 22.5 & 30.2 & 20.4 & . & 19.1 & 20.7 \\
\hline $\begin{array}{l}1985 \\
1986 \\
1907 \\
1988 \\
1989\end{array}$ & & $\begin{array}{l}30.7 \\
30.9 \\
30.9 \\
30.9 \\
30.9\end{array}$ & $\begin{array}{c}20.5 \\
.\end{array}$ & 23.6 & & 20.4 & 15.0 & 21.2 & 23.6 \\
\hline $\begin{array}{l}1990 \\
1991 \\
1992 \\
1993 \\
1994 \\
1995 \\
1996 \\
1997 \\
1998 \\
1999\end{array}$ & & $\begin{array}{l}30.7 \\
30.5 \\
30.1 \\
29.7 \\
29.2 \\
28.7 \\
28.0 \\
27.3 \\
26.5 \\
25.6\end{array}$ & 14.5 & $\vdots$ & ' & & . & 22.0 & 24.5 \\
\hline 2000 & & 24.6 & 8.0 & 23.8 & & & & & \\
\hline
\end{tabular}




\section{REFERENCES}

1. Barouch, E. and Kaufman, G.M., Probabilistic modeling of ofl and gas discovery, in Energy: Mathematics and Models, pp. 133-52, F.S. Roberts, Editor, Society for Industrial and Applied Mathematics, Philadelphia, 1976 .

2. - - The interface between geostatistical modeling of oil and gas discovery and economics, Mathematical Geology 10, 5 (1978).

3. Ciliano, R., Limaye, D., and Hu, S.D., A Comparative State-of-the-Art Assessment of Gas Supply Modeling, Electric Power Research Institute, Palo Alto, EPRI EA-201, Feb. 1977.

4. Ciliano, R., Fallah, M.H. and Limaye, D. Comparative State-of-the-Art Assessment of 0il Supply Modeling. Electric Power Research Institute, Palo Alto, EPRI EA-609, June 1978.

5. Cook, E. (Texas A\&M Un.), Economic uncertainties in assessing oil and gas resources, Presented at Am. Assoc. for the Advancement of Science Ann. Meet., Houston, Jan. 5, 1979.

6. Deffeyes, K.S. and MacGregor, I.D., World uranium resources, Sci. Am. 242 (1), 66-76 (1980).

7. DeGeoffroy, J. and Wu, S.M., A statistical study of ore occurrences in the greenstone belts of the Canadian shield, Economic Geology 65, 496-504 (1970).

8. Division of $0 i 1$ and Gas Analysis, Office of Energy Source Analysis, Assistant Administrator for Applied Analysis, Energy Information Administration, Department of Energy, Medium-Run Oil and Gas Supply Model 1977 Data Update, Washington, DC, Research Memo No. 78-015, Dec. 1977.

9. Eckbo, P.L., Jacoby, H.D., and Smith, J.L., Oil supply forecasting: a disaggregated process approach. Bell J. Esonnmirs 9 (1), 218-35 (1978).

10. Epple, D.N., Petroleum Discoveries and Government Policy, Ballinger, Cambridge, MA, 1975.

11. Everett, C., Mahn, N. and Jones, K., Division of Oil and Gas Analysis, Office of Energy Source Analysis, Assistant Administrator for Applied Analysis, Energy Information Administration, Department of Energy, Midterm Oil and Gas Supply Modeling System Description, Washington, DC, TM/ES/79-, Nov. 1978 . 
12. Feller, W., An Introduction to Probability Theory and Its Applications, Vol. II, Wiley, New York, 1966.

13. Griffiths, J.C., Exploration for natural resources, Operations Res. $\underline{2}$, 189-209 (1966).

14. Heal, G., The relationship between price and extraction cost for a resource with a backstop technology, Bell J. Economics $\underline{7}$ (2), 371-8 $(1976)$.

15. Hubbert, M.K., Energy Resources: A Report to the Committee on Natural Resources of the National Academy of Sciences -- National Research Council, Publ. 1000-D, U.S. Government Printing office, Washington, DC, 1962.

16. Hubbcrt, M.K., National Academy of Sclences repert on energy resnirces: rep1y, Bull. Am. Assoc. Petroleum Geologists 49 (10), 1720-7 (1965).

1\%. Hubbert, M.K., A Naelonal Fuels and Energy Pulley Study, Part 1, U.S. Energy Resources: A Review as of 1972, pp. 1-267, Serial No. 93-40 (92-75), U.S. Government Printing Office, Washington, DC, 1974 .

18. Kaufman, G.M., Statistical Decision and Related Techniques in 011 and Gas Exploration, Prentice-Hall, Englewood Cliffs, NJ, 1963.

19. Kaufman, G.M., Balcer, Y., and Kruyt, D., A Probabilistic Model of Oil and Gas Discovery, Am. Assoc. Petroleum Geologists Studies in Geology \#1, 1975.

20. Khazzoom, J.D., The FPC staff's econometric model of natural gas supply in the United States, Bel1 J. Economics and Managment Sc.1. 2 (1), 51-93 $(1971)$.

21. Kim, Y.Y. and Thompson, K.G., An Économic Mode1 - New 011 and Gas Supp11es in the Lower 48 States, Gulf Pub. Co., Houston, 1978 .

22. Langlois, R.N., A Perspective on the Energy Future of the Northeast: Natural Gas Discussion Paper, BNL 20781, Sept. 1975.

23. MacAvoy, P.W. and Pindyck, R.S., Alternative regulatory policies for dealing with the natural gas shortage, Bell J. Economics and Management Sci. 4 (2), 454-98 (1973).

24. McKelvey, V.E., Mineral resources estimates and public policy, in United States Mineral Resources, pp. 9-19, D.A. Brobst and W.P. Pratt, Editors, U.S. Geol. Survey Prof. Paper 820, 1973.

25. Miller, B.M., Thomsen, H.L, Dolton, G.L., Coury, A.B., Hendricks, T.A., Lennartz, F.E., Powers, R.B., Sable, E.G., and Varnes, K.L., Geological Estimates of Undiscovered Recoverable 011 and Gas Resources in the United States, U.S. Geologica1 Survey, Reston, VA, C1rc. 725, 1975. 
26. Modiano, E.M., Normative Models for Depletable Resources,MIT Operations Research Center Tech. Rep. No. 151, May 1978.

27. Momper, J.A., Domestic oll reserves forecasting, 0il Gas J."77, (33), 144-9 (Aug. 13, 1979).

28. Moore, C.L., Analysis and projection of the historic pattern of supply of exhaustible natural resources, Bul1. Operations Res. Soc. Am. 13, Supp. 1, B-38, (Spring 1965).

29. Moore, C.L., Reply to J.M. Ryan, J. Petroleum Technol. 18 (3), 286-7 (1966).

30. Pindyck, R.S., The optimal exploration and production of nonrenewable resources, J. Political Economy 86 (5), 841-61 (1978).

31. Rapoport, L.A., Boudrye, C.M. and Rohrer, M.W., FEA International Oil Supply Model, Virginia Polytechnic Institute and State University, Nov. 1976.

32. Ryan, J.M., National Academy of Sciences report on energy resources: discussion of limitations of logistic projections, Bull. Am. Assoc. Petroleum Geologists 49 (10), 1713-27 (1965).

33. Ryan, J.M., Limitations of statistical methods for predicting petroleum and natural gas reserves and availability, J. Petroleum Technol. 18 (3), 281-4 (1966).

34. Ryckborst, Determining probable maximum size of oil, gas pools, oil-inplace volumes, 0il Gas J. 78 (6) 150-4 (Feb. 11, 1980).

35. Searl, M.F., Resource assessment and supply curve development, in First IIASA Conference on Energy Resources, pp. 71-84, M. Grenon, Editor, International Institute for Applied Systems Analysis, Laxenburg, Austria, CP-76-4, May 1975.

36. Seidl, R.F., Implications of changing ofl prices on resource evaluation, in The Future Supply of Naturcmade Petroleum and Gas, pp. 113-38, R.F. Meyer, Editor, Pergamon, NY, 1977.

37. Singer, S.F., Oil resource estimates, Science 188 (1487), 401 (May 2, 1975).

38. Slichter, L.B., The need of a new philosophy of prospecting, Mining Engineering 12, 570-6 (1960).

39. Solow, R.M. and Wan, F.Y., Extraction costs th the theory of exhaustible resources, Bell J. Economics 7 (2), 359-70 (1976). 
40. Stitt, W.C. (ICF Inc., Washington, DC), Resource modeling: problems in the state of the art, Presented at NATO Advanced Research Institute on Application of Systems Sclence to Energy Policy Planning, Brookhaven Nationa1 Laboratory, Upton, NY, Nov. 12, 1979.

41. Uri, N., A Reexamination of the Estimation of Undiscovered 0il Resources in the U.S., Division of Oil and Gas Analysis, Office of Energy Source Analysis, Assistant Administrator for Applied Analysis, Energy Information Administration, Department of Energy, Washington, DC, TM/ES/79-03, 1979.

42. -- , A hybrid approach to the estimation of undiscovered ofl resources in the United States, Energy $\underline{4}$ (6), 1079-85 (1979).

43. West, J., U.S. oil-policy riddle: How much left to find? 011 Gas J. 72 (37), 25-8 (Sept. 16, 1974).

44. Wildavsky, A., Tenenbaum, E., and Albin, P., The Politics of Mistrust: An Analytical History of Oil and Gas Estimation, Lawrence Berkeley Laboratory, LBL-9889, Sept. 1979. 